\title{
A RELAÇÃO ENTRE AGENTES DE DESENVOLVIMENTO E AGRICULTORES FAMILIARES: EXTENSÃO, COMUNICAÇÃO OU DIÁLOGO
}

\author{
Mário José HENCHEN' \\ Campus Universitário de Altamira/UFPA \\ henchen@ufpa.br
}

Resumo: O presente artigo faz $u m$ breve imventário teórico-analítico das posiģoses $e$ as relagoóes dos agentes de desenvolvimento e agricultores familiares, na efetivagāo de programas de assessoria técnica para a agriculam familiar. Tais relas̄ōes adquirem maior relevância porque são aģöes educativas, pedagogicas, isto ¿́, sāo práticas sociais que, em grande medida, lanģam as bases para a constituiçāo de relaçöes democráticas que pressupūem a alteridade, indispensável na çerinaçäo de relas̆es dialógiods, notadamente, entre os atentes de destnuolvimento, tétnicos agrícolas e pesquisadors das ciêncins aprárias, de um lado e, de outro, agricultores familiares $e$ stas organizacōes. O trabalho de pesquisa foi nalizado a partir das experiencias en programas de parcerias, por meio das perepsóes dos stijeitos cuwolvidos nos processos de formação política dos agricultores familiares. Por outro lado, existe a dificuldade de romper com relagooses de bases patemalistas, dientelistas, que definiram, por matito rempo, o perfil da relagāo entre estes atores sociais, nos progranas de assessoria técnica à agricultum familiar.

Palavras chaves: Extensão nunl. Comunicaşōo nural. Agentes de desennolvinènto. Diálogo.

Abstract: The prestut article makes a brief theoretical/ analytical inventory of the positions and relationships of development agents and fanily fanners, in the accomplishment of prograns of tedmical assistance for the family agriculture. Sudh relationships acguire langer wewance because they are educational actions, pedagogic, that is, they are social practices that, in great measure, throw the hases for the constitution of democratic riationships, those that presupposes the alterity, indispensable, in the accomplishment of dialogical relationships, especially, nelationships among the deviopment agents, dgricuinural technicians and researhers of the agrarian sciences on a side and, on the other, fanily farmess and their organizations. The research was accomplished from the experiences in programs of partnerships, starting from the pereptions of the subjects inwolved in the processes of the fanily farmers' political formation. On the other hand, the difficulty of braking up with relationships

\footnotetext{
'Cientista Social, professor do Campus Universitírio de Altamira. mestre e doutorando em Sociologia pelo Programa de Pós-Graduaşio $\mathrm{cm}$ Ciẻncias Sociais -JFCH/UFPA. benchen@utpa.br
} 
of paternalist hases exists, elients, that defined for a long time the profile of the nhationship amonge these social actors, in the prograns of techmical assistance to the fumily ąericulture.

Key words: Rural extension. Rural communication. Development agents Disloger.

\section{A extensåo rural e o espírito do melhoramento agrícola}

De algumas décadas para cá, notadamente, dos anos 70, as relaçōes entre agricultores e agentes de desenvolvimento têm recebido uma atençĩo analítica especial, em particular quando se tratam de açōes ligadas à geraçăo e transferência de tecnologias. Isso se tornou possível na medida em que pesquisadores de diversas áreas do conhecimento, voltados para questōes agrárias, se propuseram a sair da pura pesquisa acadêmica, emprecndendo novas formas de intervenção e novas metodologias de trabalho. Surgia aí a possibilidade de interrogação aos agentes de desenvolvimento $\mathrm{e}$ as suas netodologias de trabalho, desenvolvidas junto aos agricultores.

Esta análise das relaçōes entre agentes de descnvolvimento, pesquisadores agrícolas e agricultores familiares parte do pressuposto de que existem diferentes formas de pensar a melhoria das práticas ou técuicas agrícolas, e sua utilizaçío em relação aos mais variados contextos socioculturais. No entanto, a noçĩo de que basta recolher e divulgar inovaçôes tecnológicas surgidas em contextos agrícolas diversos, ainda hoje se faz presente, tanto nas práticas quanto nas políticas e metodologias de trabalho das mais variadas instituiçōes de pesquisa ligadas à agricultura.

Neste sentido, dentre as várias interrogaçōes feitas às práticas dos anentes do desenvolvimento e extensionistas, podemos destacar as de Klapper (1974) que, no início da década de 1970, já afirmava que a extensão agrícola concentrout, equivocadamente, suas açöes na modernizaçăo tecnológica, sem levar em consideração a necessidade de transformação das estruturas agrárias. Assim, foram sendo implantados sucessivos programas macionais de transferência de tecnologias, cuja finalidade era aumentar a produșín e a produtividade. Não se abria, portanto, a possibilidade de mutauç̧a nas relaçöes existentes entre os agentes cconómicos, culturais. pulíticos, e os donos dos meios de produçấo; mas sim assegurava-se um refisço à dominação e à exploraçĩo já existentes na relação destes com os agricultores.

Neste sentido, partindo desta percepção acerca do agricultor laniliar, o trabalho de extensão rural foi considerado como o de assistir 
A populaçōo do campo na conquista de níveis mais satisfatórios de vida y promover adecutadas oportunidades para o efetivo desenvolvimento. Inico, ucutal, social, cultural e espiritual dos agricultores. Dentro deste marco filosóficon, a missăo principal do extensionista era a da assistência, en que o agcute técnico atuava com uma certa visão de si mesmo na condiçầs de emancipador e benfeitor dos agricultores.

A antílise centrada unicamente nas caracteristicas da técnica considera esta, segundo Rosemberg (1982), como um objeto criado pela investigiçio agronômica, que, posteriormente, pode ser transferida c incorporadia de diferentes modos pelos agricultores, neste caso, clientes passivus do processo de inovação. Esse objeto técnico, portanto, produto exclusive do conhecimento científico, se revelaria cono uma caixa preta inalterada ao longo do processo de difusĩo 2 e no qual suas próprias qualidades definiriam o êxito ou o fracasso da missão do técnico. Essa visalu dia difisĩo de tecnologias não considera of fato de que a inovaçăo ne constitui, ela própria, em um processo em que os atores envolvidos medificam \& (re)interpretam o próprio objeto técnico, processo no qual se confrontaun também as percep̧cóes e os interesses dos atores, levando entes it se posicionarem vem frente da inovação.

Neste caso, segundo o autor, dever-se-ia levar em consideração que os :ụgentes sociais implementam açōes estratégicas ${ }^{3}$ e técnicas, por meio das quais elaboram novos marcos de referências e se adaptam a cles, cul que estes mesmos agentes manipulam, modificam, (re)criam o objeto técuico cm função de sua capacidade e da necessidade de negociação, de seu conhecimento anterior, de suas informaçóes, stuas percepçóes de mundo e seus interesses.

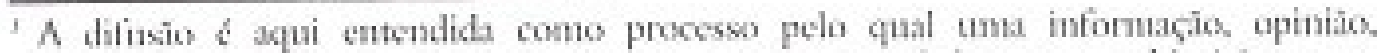

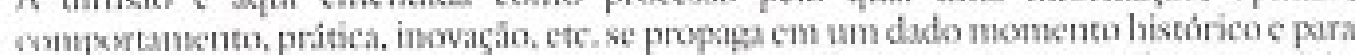
um determinado conjunto da populaşoso, A difusho é condicionada por fatores sociais,

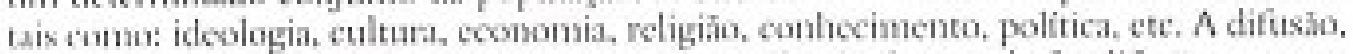

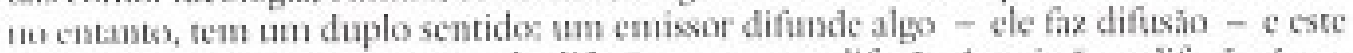

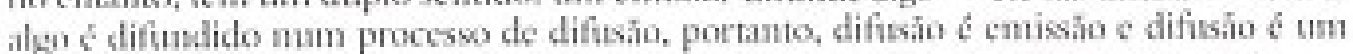
procsss jit anterior e, ao mesuno tempo, exterior ao enitente (HENCHEN, 2002),

' A cstratégia nẫo é produto de um programa ineonsciente nem de um cileulo consciente c raricmal, nas, antes de tuxdo, ela é a produto do senso prático como sentido do jogo socisl. de um jogo scxial particular, historicanenste definido e supốc uma invençăn penanente $\mathrm{e}$ indispensável pata se adaptar às situaçós indefonidanente variáveis.

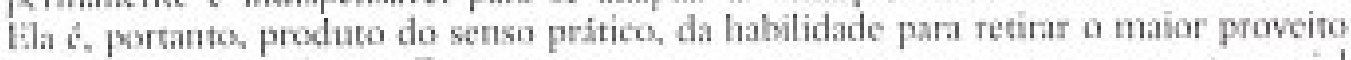
damuilo de que se dispóe. Devemos, no entanto, ter sempre presente que o ator social que realiza suas escollas é um ator socializado e que năo decide em termos individuais at cspontåneos (BOURDIEU, 1990)).
} 
1.1 Da extensão à comunicação rural: um avanço sem rupturas no modelo de intervenção

Dentre as análises do processo de extensionismo, destaca-se a análisc feita por Freire (1977) ao avaliar o modelo de intervenção na agricultura, colocado em prática por equipes de extensão rural no Brasil e no Chile, no final dos anos 60 e início dos anos 70. Sobre este aspecto, ele sugere que a falta de resultados mais profundos, em se tratando da intervenção na agricultura, no melhor dos casos, pode ser atribuída a uma visāo ingênua da realidade e, no caso mais comum, a um sentido de superioridade, de dominaçẫo com que o técnico enfrenta o camponês inscrido em uma estrutura agrária tradicional. Acentua ele, portanto, a existência de relaçóes de poder entre técnicos c agricultores, no momento $\mathrm{cm}$ que evidencia o sentimento de superioridade com que o técnico enfrenta o agricultor.

Segundo ele, o próprio conteúdo semântico do conccito de extensão é sintomático do modelo da relação entre técnico e agricultor, já que extensão significa a ação ou ato de estender algo "a" ou "até" alguém. Neste caso, do ponto de vista dos técnicos, estender o seu conhecimento, as suas técnicas aos agricultores. Esse modelo se desenvolve porque o tipo de relaçốes estruturais, rígidas e verticais, năo possibilita o espaço para o diálogo, mas para a demarcação da distância social ${ }^{4}$, e, notadamente, do lugar social dos indivíduos.

Diante destas constataçôes, o autor assegura que o diálogo somente acontece em uma situaçāo de relação $\mathrm{em}$ que o significado passe a ter a mesma significaçióo para técnicos e agricultores, c isso só se daria na comunicaçāo e na intercomunicação dos sujeitos pensantes a propósito do pensado, e nunca por meio da extensão do produto pensado de um sujeito até o outro. O termo relação indicaria, neste caso, o próprio homem em frente do mundo, como um ser do trabalho, da ação, com a qual modifica as relaçóes sociais e, neste sentido, a relaçāo se distingue do simples contato entre indivíduos.

Podemos destacar também a contribuição de Friedrich (1988) quie, ao comentar sobre os pesquisadores dos processos de comunicação cutre técnicos e agricultores, afirma que praticamente nẫo existe a

\footnotetext{
' A dlistîncia sexial é o intervalo maior ou menor que separa, no espaço social, as posiçōes de chois un mais individtos que se encontram ou pertencem a diferentes grupos ou 4lases sociais (BOURDIEU, 1990).
} 
preocupação em se questionar a posição e o interesse de quem comunica, nem o contexto em que se produz a comunicaçấo, ou a preocupaçăo $\mathrm{cm}$ relacioná-la com conteúdos, procedimentos, fatos e efeitos que a originam $\mathrm{c}$ a determinam. Atribui-sc, segundo ele, pouca ou nenhuma importância aos valores, aos comportamentos, às idéias e aos conceitos, fruto da experiência adquirida pelos agricultores na sua açăo sobre a natureza c a sua realidade sociocultural, ignorando-se que o acervo de conhecimentos gerados a partir das experiências de outros seres humanos só se adquire num processo de interação ou relacionamento entre estes, mediante uma real comunicaçâo ou diálogo entre sujeitos.

Mas, se a intençăo era a de informar - informar no sentido de levar alguma novidade "a" ou "atê" alguém -, é justificável a ênfase dada aos meios, ao material visual, às técnicas utilizadas, porque, com raras exceçōes, acreditava-se que com os mais variados auxílios técnicos e com a utilização dos melhores recursos fosse, enfim, possível alcançar melhores resultados na transferência de tecnologias. A comunicaçĩo tem, assim, o sentido do desejo ou da vontade de mudar a conduta do outro.

A questão central aqui diz respeito ao fato de que os meios de comunicaçion só adquirem relevância dentro de determinadas concepçōes de geração ou transferencia de tecnologias. Se a conviç̧âo é a de que os conhecimentos, os válores, as condutas e as atitudes podem ser transmitidas como coisas, como objetos materiais, de um lugar para outro, ć que se justificaria a ênfase dada aos meios, às técnicas ou aos mecanismos de transmissāo de informaçōes, de conhecimentos. Outro equívoco, segundo ele, bastante sintomático, diz respeito à busca dos "verdadeiros líderes" dos agricultores para com estes estabelecer uma comunicação, cujo objetivo é reduzir a distância econômica e social entre os membros da comunidade. Essa prática se mostrou equivocada, pois a suposiçẫo de que por meio dos líderes chegar-se-ia a difundir novos conhecimentos, novas condutas ou atitudes ao resto dos membros da comunidade parece estar suficientemente desmentida pela prática, e, cientificamente negada do ponto de vista sociológico.

Neste sentido, em se tratando da liderança, seja esta autoritária ou democrática, formal ou informal, líder de opiniâo ou apelidado de outra forma, o é em função de seu poder, isto é, de um conjunto de relaçốes sociais que the asseguram certo poder sobre o grupo, manifesto ou latente. Em maior ou menor grau, o líder representa ou mesmo incorpora o conjunto estruturado dos valores do sistema ao qual seus seguidores estão aderindo e, como em geral, o poder do líder emana de seu maior acervo 
de informaçōes ou do conhecimento da engrenagem social, e qualquer incremento que se the proporcione neste sentido serviria, primeiramente, para afirmá-lo ainda mais em sua posição de líder.

Neste sentido, repartir informaçōes seria o mesmo que repartir o poder, ao que, em geral, nāo estaria o líder disposto, sabedor este de que essa partilha colocaria em xeque sua posição social c, portanto, sua condiçĩo de líder. Por isso, nem mesmo as informaçōes tecnológicas terão grandes chances de serem multiplicadas pelo líder, ao menos que, e somente à medida que nâo afetem de forma alguma seu poder e seu prestígio na relação com o grupo e com outros atores sociais ${ }^{5} \mathrm{~cm}$ geral.

1.2 Novos atores entram no processo comunicativo: a possibilidade de mudanças na relação entre técnicos, pesquisadores e agticultores

Neste caso, a entrada de novos agentes neste processo comunicativo possibilita interrogaçōes quanto à eficícia ou à eficiência dos processos adotados para a geraçăo e transferência de tecnologia e, por conseguinte, ao modelo de extensão rural. Pois que, $\mathrm{cm}$ meados da década de 80 , verifica-se uma ruptura mais abrangente com o modelo de extensão rural até então vigente. Entre os marcos que demonstram, segundo Sousa (1987), a ruptura em curso com o modelo utilizado até então, encontra-se a busca do não-afastamento entre o saber acadêmico e o saber popular, $\mathrm{e}$ a abertura para a consideraçăo dos agricultores não mais como receptores passivos, mas como pessoas ativas que têm uma prática e um dizer na questão da ciência e da tecnologia para a agropecuária; em outras palavras, os agricultores passam a ser percebidos como atores sociais.

Estaria, portanto, segundo ele, desenhado um cenário $\mathrm{cm}$ que o agricultor emerge e ganha visibilidade social, passando a ser reconhecido como alguém que tem algo a dizer sobre tecnologia, dizer este que se constitui como resultado de uma prática, de um fazer, isto é, de uma trajetória social ${ }^{6}$, e que se evidencia, tanto para os agentes de

\footnotetext{
Oator social não é aquele que age em conformidade com o lugar que ocupa na organização social, na sociedade, mas aquele que, por meio de suas açóes, modifica o meio ambiente natural c, sobretudo social, no qual está inserido; modificando a divisão do trabalho, as relaçōes de dominaçăo e mestno as orientaçỏes culturais (TOURAINE, 1994).

- A noçấo de trajetória pode ser considerada uma generalização da noção de posições, à qual cla empresta uma dimensio temporal. Neste sentido, uma trajetória é uma sucessăo de posiçóes ocupadas num espaço construído, espaço este que é também afetado por transformaçoes regulares (PINTO, 2000)).
} 
desenvolvimento quanto para o pesquisador, ser de extrema importância, porque potencializa as chances de êxito do trabalho de transferência de tecnologias.

O debate em relação à extensã̃o rural continua evoluindo, e, neste sentido, Rodrigues (1985) chama a atenção para o fato de que a pesquisa deveria partir da observaçấo atenta da realidade em que se identificam os sistemas de produção e reprodução social usados pelo agricultor, e de uma série de variáveis de ordem social, política, econômica e cultural, que intervêm diretamente na produçâo. Concluindo que se fazia necessário observar atentamente a realidade em que o agricultor estava inserido.

Aos poucos, a percepçẩo da necessidade de que fosse (re)dimensionado o sistema de extensã̃o rural ganha força c desenha-se entāo, neste cenário, ainda que de forma embrionária, a possibilidade de romper com a histórica afirmação da desigualdade, característica da relação até então existente $\mathrm{cm}$ sc tratando da difusão de tecnologias. A relaçāo encre estes agentes de desenvolvimento c agricultores pode, ainda que de forma limitada, ser agora repensada a partir da proposta metodológica desenvolvida no Sistema de Convivência.

No Sistema de Convivência, como enfatizam Oliveira\&Cavalcanti (1984), a convivência ć considerada como requisito essencial para as trocas de experiências entre os técnicos e os produtores, levando-os, no diaa-dia, a definirem prioridades, avaliar resultados, (rc)programar açóes, porque a característica essencial nele contida é a possibilidade de criação de um espaço para a troca de experiências entre técnicos, pesquisadores $\mathrm{c}$ agricultores, para a definiçấo conjunta das prioridades de pesquisa ou intervenção, da avaliação dos resultados $\mathrm{e}$ da programação das atividades a serem desenvolvidas conjuntamente.

Neste caso, o conhecimento gerado a partir da convivência deveria ser fruto do diálogo que emergiria de situaçôes reais dos produtores rurais e onde estaria presente a percepção destes mesmos atores sociais sobre a necessidade de um espaço para a troca de experiências, c năo mais um espaço para a demonstração do conhecimento acadêmico do técnico ou pesquisador. Outro aspecto central contemplado nesta proposta é a idéia de que os agricultores, como individuos, têm diversas formas de ver as coisas, tềm interesses diversos e objetivos por vezes até mesmo conflitantes, percebendo-se, portanto, a necessidade de favorecer a discussāo desses interesses para aumentar as condiçóes de possibilidade de êxito do processo de extensã̃o rural e da assistência técnica. 
Portanto, da prática e do debate sobre essa prática emergem, aos poucos, novas propostas, que, por sua vez, informam novas formas de relaçōes entre agentes de desenvolvimento, pesquisadores e agricultores. Surge então a possibilidade da constituição de novas formas de intervençầ na realidade, novas relaçōes entre os atores envolvidos nestes projetos, formas essas que abrem, aos poucos, um espaço para o diálogo entre agentes de desenvolvimento e agricultores familiares.

Este debate desenvolvido em torno da extensāo atingiu também a prática de pesquisa, $\mathrm{cm}$ especial, mas nầo exclusivamente, a pesquisa junto aos agricultores familiares. As experiências realizadas nos países em desenvolvimento têm alimentado este debate a partir de diversas metodologias conhecidas como Pesquisa-participativa, Pesquisaformaçấo-desenvolvimento e Pesquisa-ação. Embora diversificadas nas suas abordagens, o que não caberia discutir aqui, estas metodologias têm alguns pontos em comum que mereceriam observaçóes cuidadosas.

Farrington\&Martin (1993), estabelecendo um quadro com as características conceituais das principais abordagens $\mathrm{cm}$ pesquisa participativa na agricultura e sobre o que deveria caracterizar as relaçōes entre agricultores e pesquisadores, apresentam duas questões pertinentes sobre os respectivos modelos: curiosidade honesta por parte dos pesquisadores, e, parceria em condição de igualdade entre agricultores e pesquisadores. Necessita-se, portanto, scgundo eles, de tempo para ganhar a confiança do agricultor, para que este possa decidir se e como ele deseja continuar os experimentos. É preciso também a flexibilidade do planejamento das atividades, consultar o agricultor, ao longo do processo de pesquisa, e mudar o modelo quando necessário.

As questōes relativas ao diálogo entre agricultores c pesquisadores, apresentadas pelos autores acima referidos, serão retomadas, seguidamente, por pesquisadores cujo objeto de análise envolve estas relaçöes. De certa forma, estavam lançadas as bases para o repensar das relaçôes que envolvem estes atores sociais quando da efetivação de açóes conjuntas, notadamente, açōes discutidas dentro de programas de parcerias entre agentes de desenvolvimento e agricultores e suas organizaçôes.

1.3 O diálogo como forma de relação entre agentes de desenvolvimento, agricultores e pesquisadores

Em se tratando do debate sobre o diálogo entre atores sociais diversos, notadamente quando estes se propōem constituir relaçōes de 
cooperação, de parceria, são significativas as contribuiçổes de Duarte (1999), que define o diálogo como a capacidade de se dirigir e de responder a outro como igual, para com ele estabelecer uma relação. Aqui reside uma questīo fundamental, pois o autor fala de estabelecer relaçöes e nã̃o apenas contatos. Desta perspectiva, o diálogo supōe e impõe um esforço e o descjo de completa reciprocidade, e a reciprocidade supōe a semelhança e a difereņ̧a, assim a alteridade é a condiçāo relacional do homem nesta relação.

Por outro lado, na construçāo de relaçōes dialógicas entre pesquisadores e agricultores, a visāo que se tem do outro também pode se constituir em um fator limitante na construção deste espaço necessário para o diálogo, porque, ainda hoje, muitos pesquisadores de formaçāo acadêmica técnica muitas vezes são levados a perceber os agricultores, c em particular os agricultores familiares, como seres indefesos, frágeis, desprovidos dos conhecimentos necessários para entender o funcionamento do sistema de produção e reprodução social, a mercê dos políticos e dos atravessadores, sem capacidade de planejamento, de gestāo, etc. Vistos desta perspectiva, os agricultores e suas lideranças dificilmente estariam em condiçōes de estabelecer relaçōes de diálogo com os pesquisadores, pois năo estariam preparados para ocuparem um espaço em condiçóes de igualdade.

Além destes complicadores nas relaçōes entre pesquisadores e agriculoores, Schaff (1966), ao se referir ao processo de comunicaçio que, por extensão, se aplicaria ao processo de díálogo, acentua o fato de que ao considerarmos o aspecto do diálogo, deveremos admitir dois tipos distintos deste: um que está enraizado em significados, e outro cujo conteúdo sầo as conviç̧ōes. Nesta última, para além da compreensão significante dos signos, há ainda o problema da adesão ou não à convíç̧ão expressa por um dos sujeitos sociais.

Neste caso, a adesāo às conviç̧ōes dos sujeitos pode se tornar um complicador nas relaçōes de diálogo, porque, dependendo das condiçóes da comunicação - pois estas podem ser estabelecidas como relaçōes de poder - os grupos podem nāo ter interesse objetivo em expressar suas conviç̧ōes, principalmente se julgarem que estas podem causar algum tipo de constrangimento ao parceiro, ou se imaginarem que tais conviç̧ōes limitam as chances de estabelecer relaçōes de diálogo. Pode acontecer também que um dos atores sociais presentes na relação nāo demonstre interesse em partilhar das conviç̧óes do outro, $\mathrm{cm}$ especial, das conviç̧óes religiosas, filosóficas, políticas e ideológicas. 
Por outro lado, Bourdieu (1990), ao falar sobre as convicçōes dos agentes sociais, lembra-nos que of fato de se pertencer a uma categoria social ou grupo profissional exerec um efeito de censura que vai muito além das coaçōes institucionais e pessoais. Isso acontece, segundo ele, porque há questōes que nāo sāo colocadas, que nāo devem ser colocadas, porque tocam nas crenças fundamentais que estão na base das práticas sociais. Temos, portanto, dois elementos complicadores das relaçóes, que são as conviç̧óes e as crenças dos atores ou agentes sociais. Desta forma, nas situaçōes em que a relação fica comprometida em função das diferentes conviç̧ões dos atores sociais, supōe-se que esta nāo evoluem para relaçōes de diálogo, porque este pressupōe a interrogação das conviç̧óes dos outros com os quais se pretende dialogar, pois o ato da interrogação, que institui ou definc uma demanda para a ação conjunta, deve autorizar e encorajar a explicitaşio das intençốes dos parceiros, c, portanto, é uma situação de exposição de ambos os parceiros à interrograçî̃o.

Mas, ao analisarmos as relaçóes sociais, devemos considerar que o essencial daquilo que se passa no processo de comunicação não está na comunicação em si mesma, mas nas condiçōes sociais que possibilitam a comunicaçâo. Portanto, a utilizaçấo de certas palavras de efeito, a escolha dos melhores meios, equipamentos e técnicas disponiveis serão de pouca utilidade c eficácia se nāo levarmos $\mathrm{em}$ consideração as condiçōes e estruturas sociais que possibilitam a comunicação.

A análise sobre a construção de um espaço social possível na efetivação de relaçōes de diálogo entre atores sociais distintos, quando estes se dispöem a trabalhar conjuntamente, deve levar em consideração algumas contribuiçónes extremamente pertinentes feitas por autores que oferecem importantes elementos para a análise que emergem da reflexão sobre suas próprias açōes como pesquisadores, e que sāo significativas porque, embora construídas a partir de olhares diferentes, convergem, no sentido de serem fruto de questionamentos que esses próprios autores sugerem, como subsídio aos agentes sociais que se propöem a discutir a qualidade de suas intervençóes junto aos agricultores.

$\mathrm{O}$ que estas contribuiçōes apresentam de significativo é o fato de nāo serem reflexóes puramente téricas ou abstratas, mas refletem, wobretudo, situaçôes concretas, e, diferentemente de outros autores, estes :ạresentam como pressuposto do diálogo a existência social de relaçōes dernocráticas. D`Incao\&Roy (1995) insistem no fato de que nāo é uecessírio supor que o diálogo só se tornaria possível entre iguais, porque 'He kontece, precisamente, entre atores sociais diferentes. Neste caso, é 
necessário, como condição para que ele ocorra, um ponto de unidade que seria o acreditar ao menos nas possibilidades renovadoras das relaçóes democráticas, e estas relaçōes democráticas seriam asseguradas pelo cncontro de pessoas autônomas, iguais, porém no direito de se expressar livremente, portanto dispostas a reconhecerem aos outros esse mesmo direito de livre expressão.

A questīo principal manifesta na posiçã̃o destes autores diz respeito ao reconhecimento do direito aos outros de se expressarem livremente não ser entendido como uma concessāo, um favor, de un dos parceiros, como uma espécie de estratégia de condescendência ${ }^{7}$, porque isto, por si só, colocaria o outro em situação de inferioridade, de dependência, de subordinaçīo, reduzindo-se ou mesmo eliminando-se a possibilidade da construção de um espaço de relaçóes dialógicas.

Em função disso, no encontro de pessoas autônomas, D' Incio\&:Roy (1995) distinguem três níveis de liberdade: a) a autonomia das pessoas, visando a que cada uma se considere livre em suas relaçōes com as outras; b) o encontro dessas pessoas no reconhecimento desta autonomia e, c) a aceitação, em comum, da submissão às regras garantidoras do exercício dessa liberdade, isto é, a submissīo à lei democrática. Neste caso, estes atores ou agentes sociais estariam, portanto, $\mathrm{em}$ situação de igualdade como interlocutores, em que saber escuthr os outros, respeitar as suas opinióes e pontos de vista favoreceria a construçāo do espaço para o diálogo entre os parceiros.

A única submissão admitida é a aceitação em comum das regras que garantem o exercício dessa liberdade, isto é, a submissão à lei democrática. Essa submissão às regras democráticas asseguraria que a expressão do ponto de vista diferente do outro não seria mais considerado como um pecado contra a causa, uma traição, porque nesta situıçio ambos teriam igual liberdade de se exprimir livremente, igual direito à interrogaçāo ao parceiro na relaçīo, e seria assim um debate regido por uma lei comum.

\footnotetext{
'As estratégias de condescendencia são situaçôes por meio da quais os agentes que ocupam uma posiç̆o superior $\mathrm{cm}$ uma das hierarquias do espaço social objetivo negam simbolicamente a distáncia social, que nem por isso deixa de existir, garantindo assim as vantagens do reconhecimento concedido a uma denegaçăo puramente simbólica da distancia que implica o reconhecimento desta distincia social real. Pode-se assim, usar as distancias objetivas de maneira a manter as vantagens da proximidade e as vantagens da distância, isto é, a distincia e o reconhecimento da distancia assegurado pela denegaçào ou recusa simbólica da distância (BOURDIEU, 1990).
} 
Por outro lado, e em se tratando de grupos distintos que se propóem efetivar açōes conjuntas, enfatizam os autores que devemos ter presente o fato de que os seres humanos têm projetos e idéias diferentes, razão pela qual é preciso respeitar a liberdade de expressāo de cada um na sua diferença, para que essa uniāo possa existir. Essas diferenças reconhecidas pelos atores permitem que o diálogo aconteça na sua forma mais profunda: na relaçāo democrática. Assim, os atores que se propõem dialogar terāo, necessariamente, que tomar decisōes que informarāo os rumos do diálogo; deverão ter o cuidado de criar condiçóes propícias para as tomadas de decisōes, pois, são as condiçōes nas quais são tomadas as decisōes que importam, uma vez que tomadas $\mathrm{cm}$ más condiçōes elas trazem em si sua própria desventura.

A construção de condiçōes que possibilitam as tomadas de decisóes requer, da parte dos parceiros, uma clareza de que se faz necessário assegurar as regras do debate coletivo do projeto, de modo que, suficientemente criticado, ele possa emergir, modificado, como projeto da expressāo coletiva, e no qual a idéia de colaboraçīo substitui a de ajuda de um dos parceiros ao outro, porque a ajuda, queira-se ou não, pressupôe uma certa dependência, uma certa inferioridade e, acima de tudo, um certo favorecimento, e requer uma contrapartida, recriando, portanto, a dependência e a submissāo que se pretendia eliminar como condição da efetivação do diálogo.

Acentuam eles ainda que, de certa forma, o sucesso do programa de parceria depende da capacidade que os agentes do projeto-pesquisadores, agricultores e sindicalistas - tiverem, por um lado, de assegurar a participação das bases - os agricultores familiares - em suas diferentes iniciativas de ordem prática e, por outro, de incorporar os resultados dessas iniciativas, a curto ou médio prazo, nas estratégias de luta sindical pelo desenvolvimento desses mesmos agricultores ou da agricultura limiliar na Amazônia como um todo.

Por isto, faz-se necessário considerar o fato de que esses programas 'k cooperaçāo, de parcerias, são eferivados em um espaço onde havia .utcriormente relações constituídas entre estes agricultores, estas lislerinģas sindicais e suas bases de sustentaçāo e que, com a chegada de trinicos e pesquisadores, essa configuraçāo anterior é agora (re)situada, ' Iur T dizer, deve ser agora negociada em outras bases.

Quando fazem referência aos programas de parcerias, falam em utcraçio referindo-se às condiçōes do trabalho conjunto de pesquisadores, 4!! ! ullores e sindicalistas no interior da intervenção programada junto 
aos agricultores e acentua que, na sua avaliação, este parece ser o caminho por excelência da produção do conhecimento novo que deverá substituir o das práticas extensionistas convencionais no trabalho de assessoria ao desenvolvimento dos agricultores familiares. Esse conhecimento, segundo eles, seria resultante do encontro de saberes dos diferentes atores em relaçāo, só possível pelo caminho da prática.

Essa nova forma de produzir conhecimento é importante, segundo eles, porque se contraporia àquela forma convencional que apenas informa quando muito, uma prática política autoritária, porque por omissão se informa, embora menos, mas uma omissão plena de significados. Neste caso, a pesquisa estaria legitimando a prática estatal das políticas definidas à revelia dos interesses específicos dos agricultores e, consequientemente, de sua participaçāo. Existe, porém, o risco de serem recriadas no seio dos programas de parcerias, as práticas autoritárias, e de que, mesmo apesar de todo o esforço empreendido, não se consiga evoluir para práticas de assessoria ao desenvolvimento, construídas no dia-a-dia, de relaçōes democráticas com estes agricultores e a partir do reconbecimento de suas especificidades ou racionalidades.

Por outro lado, Hébette (1996) lembra que estes atores ou agentes sociais, agora parceiros, falam a partir de lugares sociais diferentes, e tomam as suas posiçōes em referência a estes lugares diferentes. Assim ter-se-ia um diálogo claborado a partir de uma certa visăo de mundo. Encontramos aí uma série de fatores que podem contribuir para limitar as chances de diálogo, ou até mesmo bloqueá-lo. A parceria entre atores sociais deveria contemplar, neste sentido, um diálogo como forma de relação entre grupos sociais ou categorias que se situam de formas diferentes na sociedade, mas que se propóe a discutir formas negociadas de intervenção na realidade, objetivando o desenvolvimento de açóes na regiã̃o.

Em relaçāo às possibilidades $\mathrm{e}$ aos limites para se avançar na consolidação de relaçōes dialógicas entre atores sociais diversos, faz-se necessário perceber, segundo ele, que os interesses $\mathrm{em}$ comum, que sīo as bases do grupo ou da classe e que não excluem competiçio, tensōes e conflitos internos, servem para moldar universos de convivência e de comportamento muito diversos $\mathrm{c}$, às vezes, até mesmo contrastantes, $\mathrm{e}$ que o desconhecimento ou a não consideração deste fato pode dificultar as relaçōes entre os atores sociais que tentam construir o diálogo na condição de parceiros em um programa de pesquisa.

Comentando acerca de como os agentes ou atores envolvidos no processo de diálogo percebem-se ou săo percebidos nestas relaçōes, 
o referido autor afirma que, independentemente da sua vontade, os pesquisadores, em geral, são percebidos ou definidos pelos agricultores como detentores de soluçóes que são a chave para a resoluçâo de problemas que os afligem. Muitas vezcs, porém, os próprios pesquisadores sentemse confortáveis com a perspectiva de que sejam imaginados ou percebidos como detentores de saberes e de conhecimentos que funcionariam como remédio no tratamento de problemas ligados às atividades dos agricultores, e, desta forma, acabam contribuindo para reproduzir a imagem que os agricultores têm sobre eles.

Nestc caso, acredito, a diferença nas posiçōes adotadas entre Hébette (1996) e D'Incao\&Roy (1995), se evidencia, de certa forma, em se tratando da visão sobre a necessidade ou a decisão em relação à intervençāo junto às equipes que se propōem colocar em prática projetos coletivos. Por seu lado, o primeiro assume claramente uma postura de incentivador da intervenção, porém, de uma forma de intervençāo dialogada, negociada entre os atores sociais, $\mathrm{cm}$ que o pesquisador participa, interroga c é interrogado pelos parceiros na elaboração c na definiçāo das açóes conjuntas; enquanto que a segunda propóe uma postura de nāo-intervençāo direta, uma não intervençî́o que acaba sendo, segundo a autora, uma contribuição ao processo de diálogo entre os atores envolvidos na açāo conjuntù.

A primcira proposta - a da intervenção dialogada, negociada apresenta, acreditamos, algumas limitaçōes que precisam ser superadas. Uma delas diz respeito à possibilidade de se manter um distanciamento necessírio que possibilitaria ao pesquisador vencer o descjo de trocar de lugar com outros atores sociais presentes no diálogo. E, segundo estes, faz-se necessário superar o descjo dos pesquisadores ou técnicos $\mathrm{cm}$ ocuparem a cadcira vazia do chefe, assumindo uma posiçāo privilegiada que a sua formação profissional the possibilita, mas que scria prejudicial ao diálogo c anularia a possibilidade de construção de relaçôes democráticas entre os atores envolvidos na parceria.

Já a segunda proposta - a da não intervençāo direta - parece dar pouca atençî́ a to fato de que, mesmo em não se intervindo diretamente ta situaçāo de diálogo propriamente dita, a simples presença que interroga as práticas dos atores sociais presentes, por si so, já se constitui em intervençâo, porque essa presença promove uma (re)visão das posiçóes assumidas na situação de diálogo.

Por sua vez, Muchagata (1994), assegura que tais diferenças, c dentre e'stis as diferenças culturais e institucionais, informam, por assim dizcr, 
os lugares e as posiçōes sociais ocupadas pelos atores na sociedade. Atores estes que levam, para as relaçōes com os parceiros, suas expectativas como atores ou agentes sociais com visôes de mundo diversas. Aponta a autora, uma série de dificuldades encontradas na construção do diálogo entre os pesquisadores e os agricultures organizados. Chama nossa atençiò ao enfatizar que talvez mais do que a adequaçōo ou não à realidade regional, o que bloqueia os pesquisadores pode ser a pereepsăo dos agricultores que os relegavam ao restrito papel de médicos, que deveriam dar suas consultas da mesma maneira que simples prestadores de serviços, preocupados apenas em aspectos técnicos, c nâo os viam como verdadeiros colaboradores, capazes de participar ativanente do seu desenvolvinento.

Essa visío que $\mathrm{se} k \mathrm{~km}$ de outro se constitui em um dos fatores limitantes na construşāo de un espaço social de relaçóes de diálogo entre agricultores e pesquisadores, pois, tratando-se das necessidades ou demandas de pesquisas sugeridas pelos agricultores, a autora acredita que as questôes levantadas pelos parceiros são lançadas em relação à visî́o que eles têm sobre as competências $\mathrm{c}$ as funçōes de seus parceiros, e que recusar-se a dar prosscguimento a uma demanda seria bloquear a relaçīo e perder uma exeelente ocasião de conhecer melhor esta percepçio do parceiro. Desta mesma perspectiva, os pesquisadores também lançam on colocam as suas questōes em função da sua visāo de mundo, da visã̃o de ciência e da visĩo que têm sobre os agricultores. Necessitariam estes, portanto, nảo somente interrogar os parceiros, mas interrogarem-se a si mesmos sobre seus pontos de vista acerca dos agricultores.

\section{Consideraçōes Finais}

Parece ficar clara a necessidade de cue enda um dos parceiros interrogue-se sobre como o Eu perecbe u Outro na relaçāo de diáloggo dentro da parceria. Por outro lado, as pesţuisa tềm, em grande medida, funcionado em parte como se este espaço prara o diálogo já existisse, enquanto que, na realidade, cle se constitui cm tm objetivo a ser buscado e constituído permanentemente. E, como as relaçóes sociais sio coisas que se fazem e (re) fazem a partir de um trabalho de mobilizaçāo, de barganha, de neggociação, de regareio, de mediaçios, devemos estar atentos para o fato de que não existe nenhuma clance de se decretar diálogo, isto é, de perceber que ele, o diálogo, precisa ser construido a partir de relaçóes de alteridade, em que ambos os parceiros estīo autorizados a colocar demandas, a levantar questionamento, a fazer interrogaçōes. 
A constituição de um espaço de relaçōes sociais com base no diálogo, requer, da parte dos parceiros, uma tomada de posição, porque supóe a conciliação provisória e renovada de interesses distintos e até mesmo conflitantes, cuja defesa deverá ser permanentemente buscada pelos parceiros, fazendo-se necessário o reconhecimento da diferença de interesses e a compreensĩo de que a relação de parceria envolve níveis de relaçōes pessoais e interpessoais com objetivos e estratégias distintas. E estas estratégias são definidas por situlaçōes c posiçōes sociais, econômicas, políticas, religiosas e culturais de cada um dos atores, grupos ou instituiçôes presentes ou envolvidas na parceria.

Por outro lado, a análise necessária para a elaboração de um programa de parceria com base em relaçôes dialógicas deve considerar que uma parceria envolve relaçōes complexas nas tomadas de decisões. Decisões estas que visam a mudar a realidade, sendo esta realidade múltipla e composta por diferentes percepçôes culturais, por diversos interesses sociais em jogo, e que, de certa forma, constituiu-se, como realidade social, a partir das lutas sociais e políticas que evidenciam, nas relaçōes, quer de cooperação ou conflito, as posiçōes dos atores presentes em tal realidade.

A participação dos atores sociais é fruto da negociação, da barganha, e, no limite, nåo existe uma única forma adequada de participar. Mas é, sobretudo, a forma de conduzir o processo de diálogo que define as chances $\mathrm{c}$ os limites deste, porque, tanto nas situaçōes de parceria quanto nas relaçōes sociais $\mathrm{em}$ geral, as regras do jogo social não devem ser definidos como uma espécie de decreto-lei, como, aliás, acontece na maioria das vezes entre compradores e vendedores de força de trabalho c que são, não por acaso, a base dos diversos programas de assessoria estatal, quando estes concebem os agricultores familiares como estando na situaçāo de clientes de seus serviços de reforma agrária, de assessoria técnica.

Nas relações entre os parceiros, por certo, as regras do jogo democrático só se constituirão em regras observadas por todos $\mathrm{sc}$ forem negociadas entre os atores sociais presentes e em relaçăo, c se, por assim dizer, expressarem a necessária cumplicidade entre parceiros. É isto que possibilita o acordo colctivo entre grupos ou sujeitos distintos, cuja finalidade poderá criar as condiçōes de possibilidade para mudar a realidade social, isto é, o conjunto das realizaçōes dos seres humanos. 


\section{REFERÊNCIAS}

BOURDIEU, P. Coisas ditas. Sāo Paulo: Brasiliense, 1990.

D'INCAO, M. C. \&ROY, G. Nós cidadãos: aprendendo c ensinando a democracia. Rio de Janciro: Paz e Terra, 1995.

DUARTE, J. C. (Org). Polis: Enciclopédia Verbo de Sociedade e do Estado, Lisboa: Editorial Verbo, 1999.

FARRINGTON, J.\&MARTIN, A. Farmer Participation in Agricultural Research: a review of concepts and practices. London: ODV/Ocasional Paper, 1988.

FREIRE, P. Extensâo ou comunicação? Rio de Janciro: Paz e Terra, 1977.

FRIEDRICH, O. A. Comunicação rural: proposição crítica de uma nova concepção. $2^{2}$. ed. Brasilia: EMBRATER, 1988.

HÉBETTE, J. A relação pesquisadores: agricultores. Diálogo, parceria, aliança? Uma análise estrutural. In: Agricultura Familiar: PesquisaFormaçäo-Desenvolvimento. v. 1, n. 1. Belém: UFPA/CAP/NEAF, 1996.

HENCHEN, M. J. O diálogo como relaçăo entre agricultores e pesquisadores: a experiência do PAET na Transamazônica. Belém: UFPA, 2002.

KLAPPER, J. Efectos de la comunicacion de massas. Madrid: AGUILAR, 1974.

MUCHAGATA, M. G. A construçāo do diálogo entre pesquisadores e agricultores através da experiência do CAT (Centro Agroambicntal do Tocantins) em Marabá/ PA. Laboratório S6cio-Agronómico do Tocantins, LASAT/CAT. In: Recherches-système en agriculture et dévelsppenent rural. Sympósium Internacional. Montpellier, France, 1994.

OLIVEIRA, M. M\&CAVALCANTI, C. P. B. O "sistenua de convivência" como processo de trabalho extensionista. Cadernos de difusáo de tecnologia. v. 1, n. 2. Brasilia: EMBRAPA, 1984.

PINTO, L. Pierre Bourdieu e a teoria do mundo social. Rio de Janciro: FGV, 2000.

RODRIGUES, C. M. Difusấo de tecnologia: uma abordagem além do circuito tecnológico. Cadernos de difusão de tecnologia. v, 2, $n^{\circ} .2$. Brasília: EMBRAPA, 1985. 
ROSEMBERG, N. Inside the Black Box. Cambridge: Cambridge University Press, 1982.

SCHAFF, A. Introducion a la Semantica. México: Fondo de Cultura Econômica, 1996.

SOUSA, I. S. F. de. Difusão de tecnologia para o setor agropecuário: a experiência brasileira. Cadernos de difusão de tecnologia. v. $4, \mathrm{n}^{\circ} .2$. Brasilia: EMBRAPA, 1987.

TOURAINE, Alain. Crítica da modernidade. Petrópolis: Vozes, 1984.

Artigo recebido no dia 13 de julho de 2008 e aprovado no dia 27 de agosto de 2008. 